\title{
Advanced ground freezing method and its applications in underground construction
}

\author{
Mikhail Shuplik ${ }^{1}$ and Petr Nikolaev ${ }^{1 *}$ \\ ${ }^{1}$ National University of Science and Technology MISIS, 119991 Moscow, Russian Federation
}

\begin{abstract}
During underground construction works in complex geological environment, special ground improvement techniques have to be used. One of them is artificial ground freezing (AGF). It can be applied in diverse projects in dense populated urban areas that place constraints on an application of other ground improvement methods. In Russia in the late $1980^{\text {th }}$ was developed one new method of ground freezing. It uses solid carbon dioxide (SCD) that is loaded directly into freeze pipes, where it sublimates. As the result, the quite low temperature of freezing can be achieved easily. In this article are discussed several first application cases of this method. The results of these projects allow SCD freezing became widely used ground improvement method in Russia.
\end{abstract}

\section{Introduction}

Artificial ground freezing method was proposed more than 100 years ago in the mining industry [1]. Since that time, the application field of this method became wider. Nowadays, this method is regularly used for construction works in urban areas. For example, it was applied during underground constructions in USA [2], China [3], Germany and Netherlands [4] etc.

Several freezing methods, that used different refrigerants, were proposed, such as: "brine" freezing, liquid nitrogen (LN) freezing and solid carbon dioxide (SCD) freezing. The last of these methods was proposed 40 years ago independently in [5] and [6], and since that time was applied in several construction projects in Russia and worldwide.

According to [5,6], during ground freezing with using solid carbon dioxide, it is loaded directly into freeze pipes. Carbon dioxide takes heat from the surrounded soils, and as the result, it sublimates. The temperature in freeze pipes is lowered up to $-78.9^{\circ} \mathrm{C}$. Water around pipes freezes and the ground-ice-wall is formed. Carbon dioxide is regularly loaded into the columns to maintain its level above the water table. (Fig. 1)

This method has significant advantages compare to classical freezing methods: a freezing system has no moving parts, it is silent, and requires no major services, such as water or electricity; refrigeration is fast, typically taking up to one week to form a contiguous ice-wall. Their site installation is much easier, and as a result, faster.

According to [6,7], this method can replace a brine freezing method with a freezing plant up to $200 \mathrm{~kW}$ power.

\footnotetext{
*Corresponding author: pvnikolaev@ misis.ru
} 


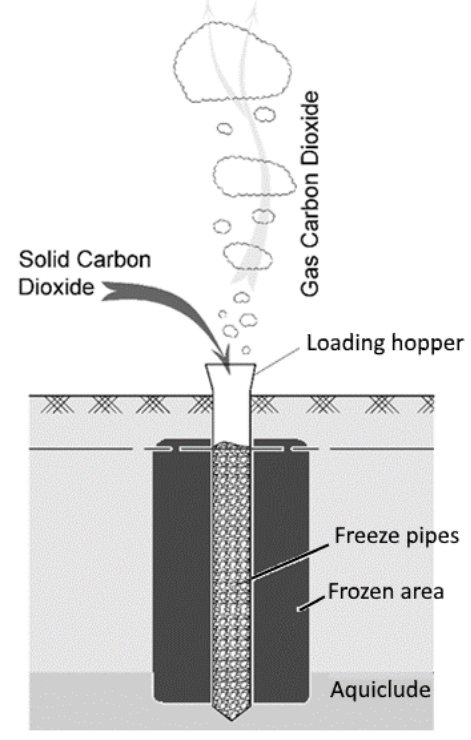

Fig. 1. Solid carbon dioxide method of ground freezing

Nowadays, in Moscow, SCD freezing method fully replace LN freezing. That happened because of several reasons. First, due to more complicated installation process of LN freezing system, the total freezing period for LN and SCD freezing are approximately the same. At the same time, the cost of LN freezing is much higher. The last reason is that LN freezing is a complicated and dangerous method, that need special cautiousness during the workflow. At the same time, SCD freezing can be realized without any special preparation by unqualified workers.

In this article, several application cases are discussed. All of them took place in Moscow, Russia from 1988 to 2008, and were presented in Russian in [6,8-11].

Analysis of these experiences allow to elicit some possible problems and formulate recommendations for effective application of this method for future construction works.

\section{SCD freezing applications}

\subsection{An underground car parking}

Solid carbon dioxide ground freezing was firstly applied in October, 1984 during construction of an underground car parking that locates close to the VDNKh exhibition in Moscow. There were several freezing zones [6].

At one of these freezing zones, $100 \mathrm{~m}^{3}$ of fine saturated sand were frozen. The layer of this soils is located at the $17 \mathrm{~m}$ depth and has the thickness of $8 \mathrm{~m}$. Freezing was made by 11 freezing pipes with the $219 \mathrm{~mm}$ diameter.

$50 \mathrm{~kg}$ solid carbon dioxide blocks (different types of SCD presented in Fig. 2) were transported to the construction site by refrigerator trucks. Blocks placed near the freezing pipes and were covered with canvas sheets. Before putting into the pipes, blocks were crashed into $50 \mathrm{~mm}$ pieces. These pieces were loaded into the pipes manually with using specially constructed loading hoppers. The refrigerant was usually loaded until a pipe was fulfilled. The next load happened when the level of SCD dropped to minus 15-17 m. As the result, the freeze pipes were constantly fulfilled with SCD in the freezing area. 


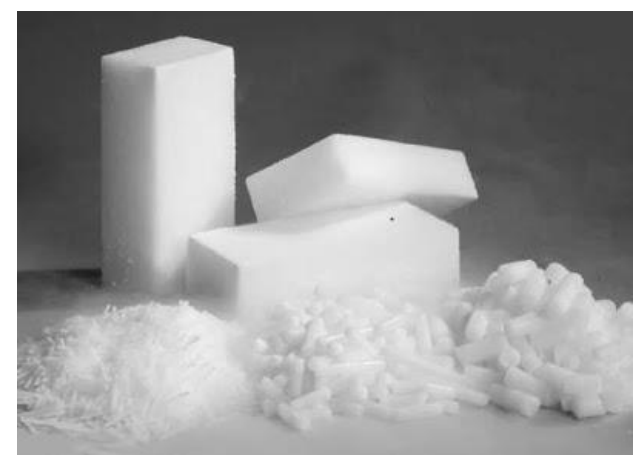

Fig. 2. Solid carbon dioxide in blocks and granules with different diameters

One of the problems, that was discovered, was the formation of water ice obstructions in the pipes. That happened due to poor tightness of the pipes, which does not prevent the leakages of water from the surrounded grounds.

The juxtaposed ice cylinders came into the contact on the fifth day when the distance between them was $1 \mathrm{~m}$; and on the fifteenth day for the distance $1.8 \mathrm{~m}$. For freezing $1 \mathrm{~m}^{3}$ of soils, $800 \mathrm{~kg}$ of SCD were needed. However, according to calculations [7], nearly half of the solid carbon dioxide were wasted on cooling overlaying unsaturated soils.

\subsection{Lefortovo tunnels}

During construction of the Lefortovo tunnel in Moscow in 2000, a TBM entry pit was being built. However, the workflow was interrupted by some geotechnical problems $[9,11]$.

The pit was designed with sheet pilings that were used for protection against waterbearing soils (see Fig. 3). However, during the excavation at the $19 \mathrm{~m}$ depth, three disjunctions of the sheet pilings were found. Water and soils began rapidly come from these holes into the pit. For preventing flooding, cantledge berms were organized under these holes.

The solution that was applied for this problem was using SCD. Near these disjunctions, several boreholes were bored, in which freeze pipes were installed. The diameter of pipes was $168 \mathrm{~mm}$. Afterwards, granulated solid carbon dioxide was loaded into these freeze pipes. The soils were successfully frozen after 8 days of freezing.

At this construction site, the granulated SCD was used for the first time. The diameter of granules was between 10 and $15 \mathrm{~mm}$. However, due to some interruptions in their delivery, SCD blocks were also used. They were crashed just before loading, because these crashed SCD particles cannot be store for more than an hour as they formed monolithic mass, that had to be crashed again. When this crashed SCD was used, many obstructions in the pipes were formed. They were liquidated by stopping loading SCD into the pipes for up to 6 hours. The amount of SCD waste during its transportation and loading was around $20 \%$.

\subsection{Sewage collector under "Bogatirkyi most" street}

In 2000, a sewage collector was constructed along "Bogatirskyi most" street in Moscow [8]. There were several freezing zones, where SCD was used.

The connection between the new collector to the existing system was design to construct under protection of the ice-wall, that created by the "brine" freezing method with pipes' temperature around minus $23{ }^{\circ} \mathrm{C}$ (Fig. 4). 

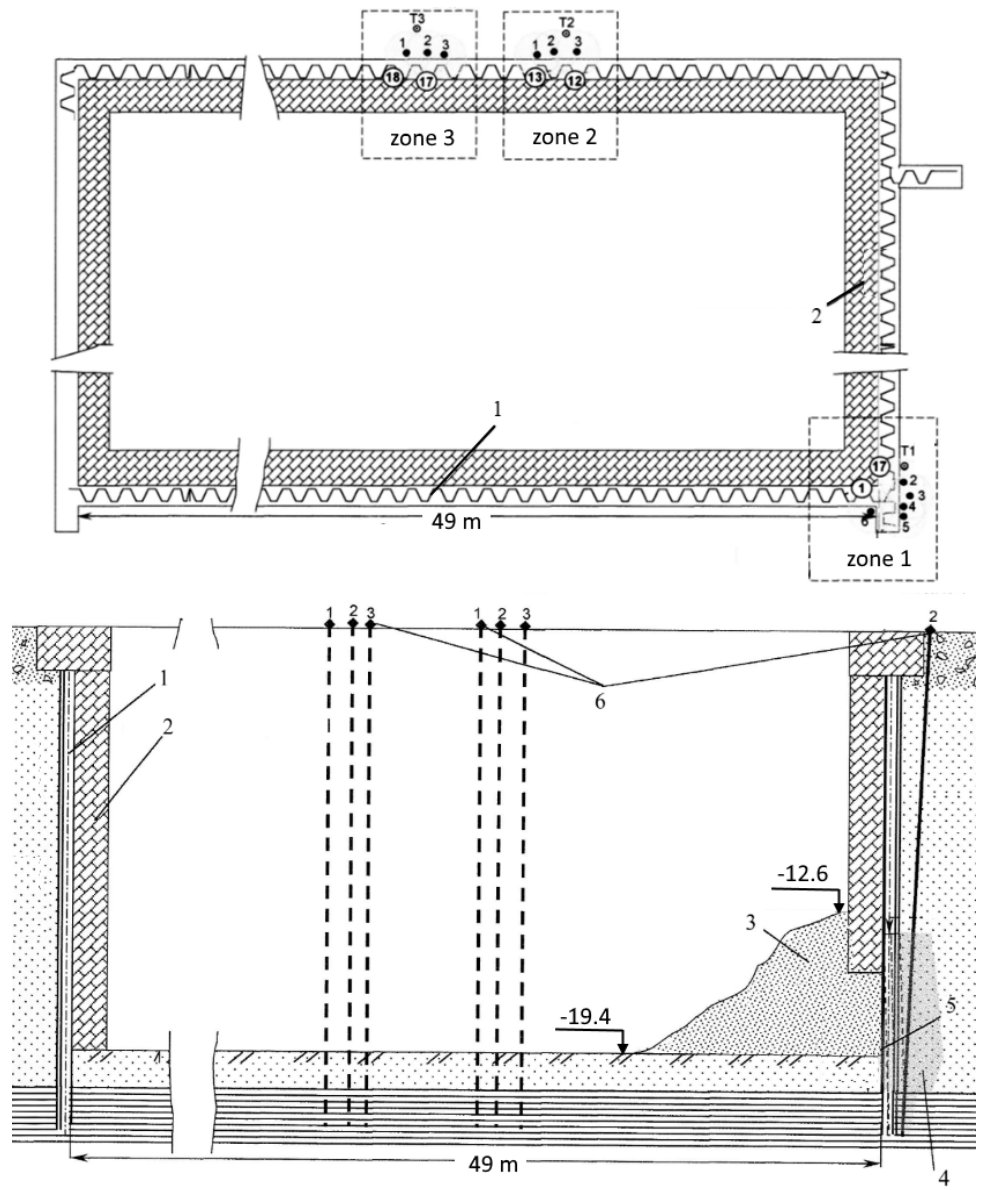

Fig. 3. Artificial ground freezing during construction of Lefortovo tunnel in Moscow [11]:1 - sheet piling; 2 - concrete reinforced walls of the pit; 3 - cantledge berm; 4 - freezing zone; 5 -disjunctions of the sheet pilings; 6 - freeze pipes.

After 30 days of freezing, the state of thermal equilibrium was set. It happened because the water temperature within the existing collector was more than $25^{\circ} \mathrm{C}$.

The solution that was applied for this problem was using SCD. The freeze pipes that adjacent to the junction tunnel were reequipped: the inner pipes were dismantled, and the brine was evacuated. Afterwards, granulated solid carbon dioxide was loaded into these freezing pipes. The cofferdam was created after three days of freezing.

\subsection{A vertical shaft for the Moscow subway system}

Artificial ground freezing with using solid carbon dioxide was used during the construction of a vertical shaft for the Moscow subway system in 2001 [12]. The diameter of the shaft is $5.5 \mathrm{~m}$ and it is $26 \mathrm{~m}$ deep. Geological situation includes: the layer of unsaturated fine sand from the ground surface to the $10.5 \mathrm{~m}$ depth, the layer of fully saturated sand from $10.5 \mathrm{~m}$ to $15 \mathrm{~m}$, the layer of cracked limestone from $15 \mathrm{~m}$ to $18 \mathrm{~m}$, and underlying layer of clay.

The design project involved using bored-secant piles as a cofferdam (see Fig. 5).

During the excavation at the $10.5 \mathrm{~m}$ depth, several disjunctions of piles were found out. These gaps were up to $150 \mathrm{~mm}$. The analysis of the problem showed that for guaranteeing safety of excavation work, artificial ground freezing should be used. 

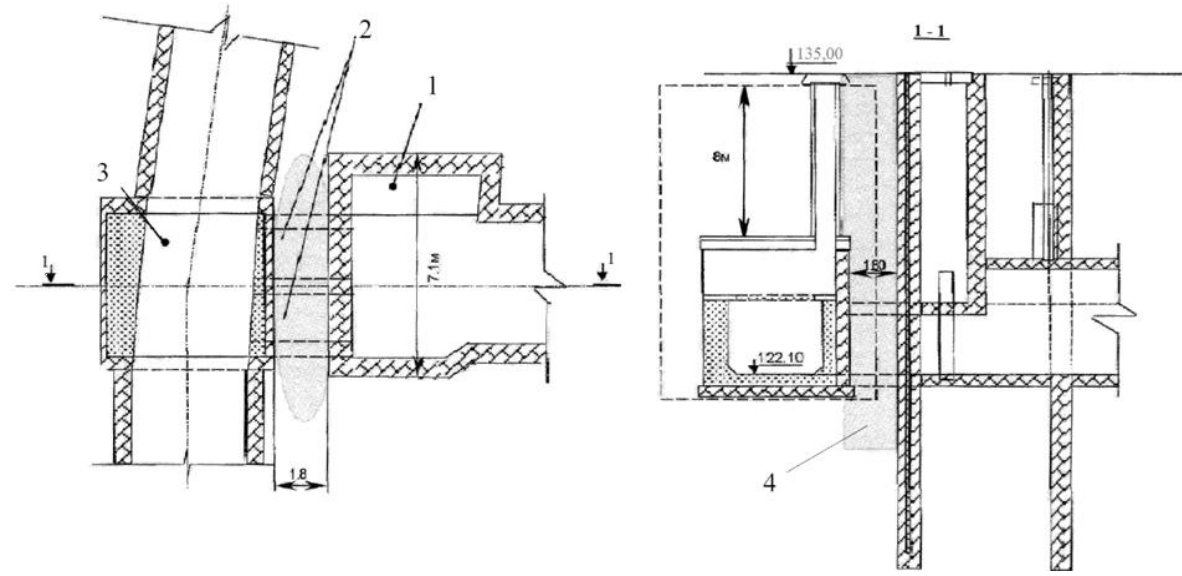

Fig. 4. Sewage collector conjunction [8]: 1 - new collector; 2 - junction tunnel; 3 -existing chamber; 4 - freezing area.

The project provided a local freezing of soils from $10 \mathrm{~m}$ to $19 \mathrm{~m}$ depth. Granulated SCD was used. The diameter of granules was $10-15 \mathrm{~mm}$.

There were 32 main freezing pipes and 4 additional freezing pipes that were bored after well trajectory surveillance. The diameter of pipes was $114 \mathrm{~mm}$. The distance between them was up to $0.8 \mathrm{~m}$.

The freezing time was 8 days. During this time the level of SCD in the pipes was maintained at the $8 \mathrm{~m}$ depth. The project thickness of the ice-wall was $0.8 \mathrm{~m}$.

During workflow, there were granulated SCD delivery interruptions. During these periods, SCD blocks were used. When they were crashed, solid carbon dioxide "snow" was formed. When it was loaded into the pipes, it often sealed them.

The estimated loss of SCD during transportation, storage and crashing was up to $50 \%$.

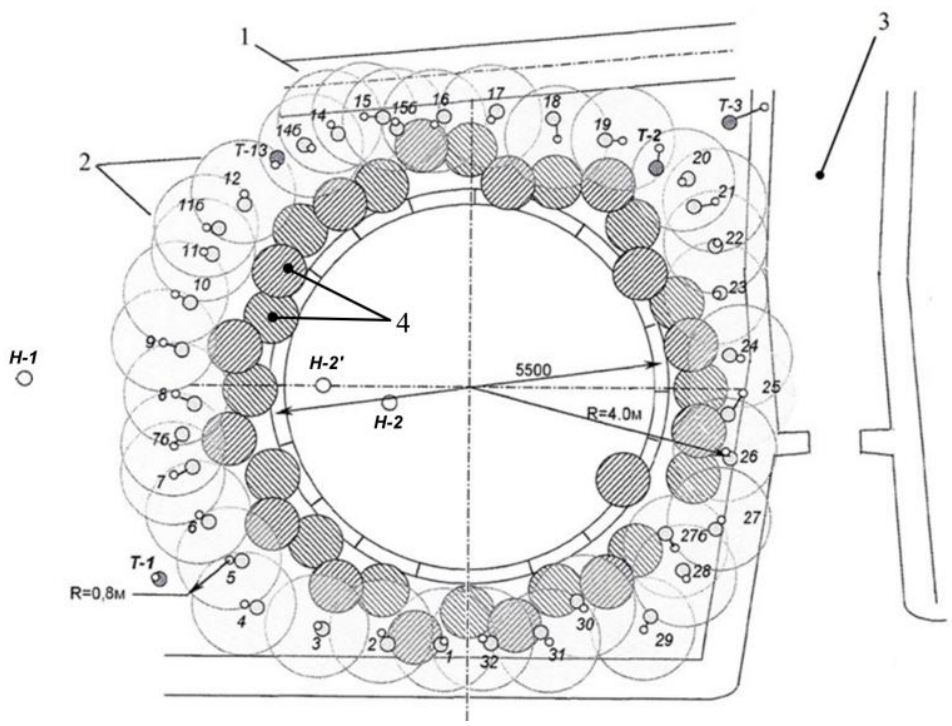

Fig. 5. Artificial ground freezing around a vertical shaft for the Moscow subway system [12]. The location of secant piles and freezing pipes at the $19 \mathrm{~m}$ depth. 1, 3- underground structures closed to ground surface (a collector and a foundation of an adjacent building); 2 - ground-ice cylinders; 4 bored-secant piles. T-1, T-2, T-3 - thermometric wells; H-1, H-2, H-2'- hydrogeological wells. 


\subsection{A service cross passage between Serenoborsk tunnels}

During construction of Serenoborsk tunnels in Moscow in 2007, artificial ground freezing method was used. The service cross passage between tunnels is located in water-bearing silts. As a lining, reinforced concrete blocks were use (for more information about modern support systems for transport tunnels, see $[13,14])$.

For protecting construction works, the ground-ice wall was designed around this service tunnel. The ice-wall was formed by "brine" freezing method. For more information about this freezing work, see [10].

When the ice cofferdam was created, excavation began. However, during support erection, an unfrozen zone was found. The amount of unfrozen saturated soils was estimated as $1.5 \mathrm{~m}^{3}$. This small area prevented finishing the construction work.

For fast solving of this problem, an interesting solution was proposed. The tunnel wall was frozen by SCD, that was loaded in a special box adjacent to the wall (see fig. 6). The period of freezing was 2 days.

For controlling the level of $\mathrm{CO}_{2}$ in the tunnel atmosphere, inflow exhaust ventilation system was used. The concentrations of gases were measured every 15 minutes. Monitoring is an essential part during underground construction which includes such difficulties [15].

This project showed possibility to use solid carbon dioxide freezing method for freezing soils from underground constructions.

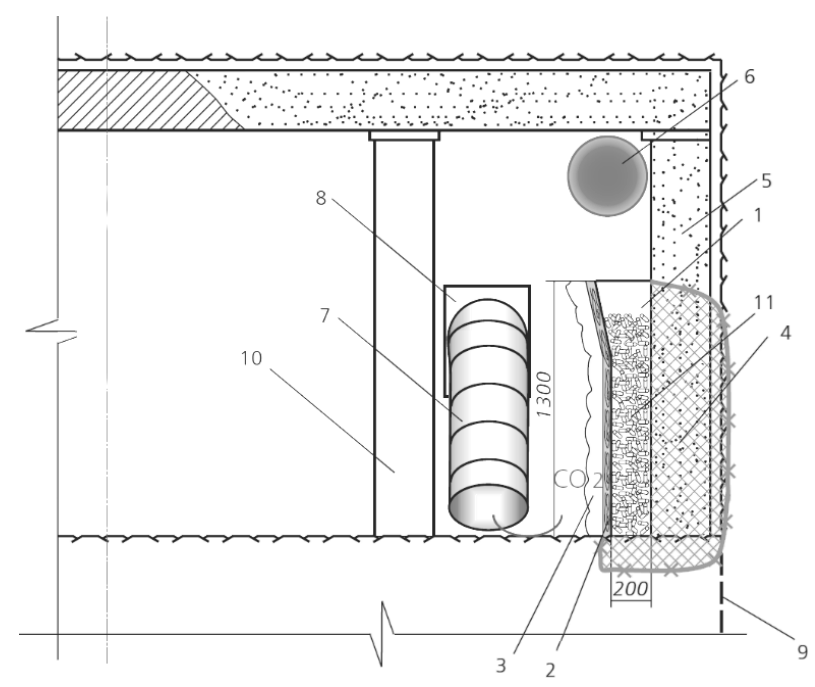

Fig. 6. Freezing of soils beyond a tunnel wall. 1 - box; $2-40 \mathrm{~mm}$ timber planks; $3-80 \mathrm{~mm}$ heatinsulating layer; 4 - frozen area; 5 - temporary lining; 6 - inlet ventilation; 7 - outlet ventilation; 8 canal to one of the main tunnels; 9 - contour of the constructing service passage; 10 - temporary lining arch; 11 - granulated solid carbon dioxide.

\section{Discussion}

Summary list of discussed application cases is presented in Table 1.

The analysis of practical experiences allows to define several common characteristics of these freezing projects.

First of all, SCD freezing was used mainly for rapid ground freezing for emergency applications or for cases when initially used ground improvement techniques were not effective. In these cases, if SCD freezing was chosen initially, the cost of construction works would be significantly lower. 
Secondly, the average consumption of SCD was between 120 and $800 \mathrm{~kg} / \mathrm{m}^{3}$. In most of cases, the high consumption was due to significant losses during transportation, storage, and loading. Rough estimation of these losses shows that approximately $50 \%$ of all SCD was wasted. One important factor that defines the average consumption is a frequency of loading. It is defined by the acceptable fluctuation of SCD level that is keeping in freezing pipes.

Thirdly, the design of SCD needs special attention to the properties of soils and consideration of them in the design project. The properties define the consumption of the refrigerant, and how it changes during the process of freezing.

Table 1. List of solid carbon dioxide freezing applications

\begin{tabular}{|c|c|c|c|c|c|c|c|c|}
\hline \multirow{2}{*}{ 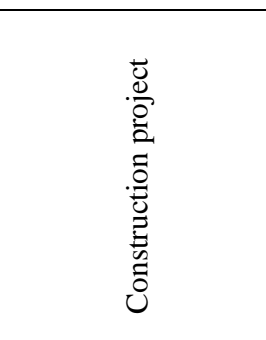 } & \multirow{2}{*}{ 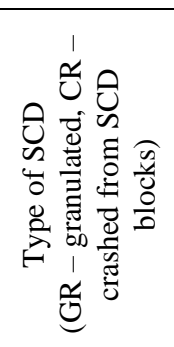 } & \multicolumn{3}{|c|}{$\begin{array}{l}\text { Parameters of } \\
\text { freeze pipes }\end{array}$} & \multirow[b]{2}{*}{ 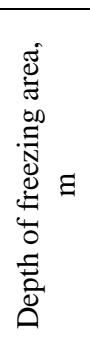 } & \multirow[b]{2}{*}{ 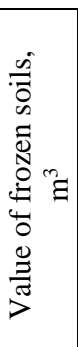 } & \multirow{2}{*}{ 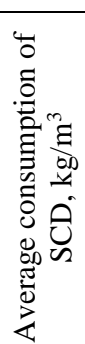 } & \multirow[b]{2}{*}{ 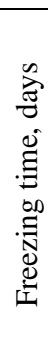 } \\
\hline & & 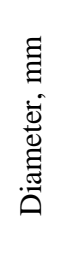 & 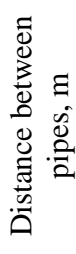 & $\begin{array}{l}\text { ¿े } \\
\text { है } \\
\text { 之 }\end{array}$ & & & & \\
\hline \multirow{4}{*}{$\begin{array}{l}\text { An underground } \\
\text { car parking }\end{array}$} & $\begin{array}{c}\text { GR } \\
(3-10 \mathrm{~mm})\end{array}$ & 114 & 5 & 2 & $0-3$ & - & 180 & 5 \\
\hline & \multirow{2}{*}{$\begin{array}{c}\text { CR } \\
\text { (up to } 50 \\
\text { mm) }\end{array}$} & \multirow[t]{2}{*}{219} & 1 & \multirow[t]{2}{*}{11} & \multirow[t]{2}{*}{$17-25$} & \multirow[t]{2}{*}{100} & \multirow[t]{2}{*}{800} & 5 \\
\hline & & & 1.8 & & & & & 15 \\
\hline & $\mathrm{CR}$ & 146 & 0.9 & 8 & - & 7 & 485 & - \\
\hline \multirow{4}{*}{$\begin{array}{l}\text { Sewage collector } \\
\text { under "Bogatirkyi } \\
\text { most" street }\end{array}$} & \multirow{4}{*}{$\begin{array}{c}\text { GR } \\
(8-10 \mathrm{~mm})\end{array}$} & 100 & - & 6 & $6-16$ & - & - & 3 \\
\hline & & - & - & 3 & $\begin{array}{c}11.5- \\
13.5\end{array}$ & - & - & - \\
\hline & & - & - & 4 & $19-21$ & - & - & - \\
\hline & & - & - & 5 & $11-21$ & - & - & - \\
\hline \multirow{3}{*}{$\begin{array}{l}\text { The construction of } \\
\text { Lefortovo tunnel }\end{array}$} & & \multirow[t]{3}{*}{168} & - & 5 & - & \multirow[t]{3}{*}{500} & \multirow{3}{*}{223} & \multirow{3}{*}{8} \\
\hline & $(10-15 \mathrm{~mm})$ & & - & 3 & - & & & \\
\hline & GR and $\mathrm{CR}$ & & - & 3 & - & & & \\
\hline $\begin{array}{l}\text { A vertical shaft for } \\
\text { Moscow subway }\end{array}$ & $\begin{array}{c}\text { GR } \\
(10-15 \mathrm{~mm})\end{array}$ & 114 & 0.8 & 36 & 10-19 & 800 & 160 & 7.5 \\
\hline
\end{tabular}

\section{Conclusion}

Solid carbon dioxide ground freezing is an effective method of ground improvement. Presented application cases proved that this method can be widely used for freezing soils in urban underground construction works. As the result, since 2008 this freezing method was used on several other projects, where up to $2000 \mathrm{~m}^{3}$ of soils were frozen. The future studies should develop the engineering method for designing the parameters of this freezing methods. It allows to reduce the amount of SCD that is needed for realization of this freezing method.

\section{References}

1. N.G. Trupak N G 1954 Artificial groud freezing during construction of vertical pits (in Russian) (UgleTechIzdat, Moscow, 1954) 
2. P. Schmall, A. Dawson, Proc. of the Ins. of Civ.Eng.-Gr. Impr., 170, 159-172 (2017)

3. J. Hu, Y. Liu, Y. Li, K. Yao, J. Civ. Eng. 00, 1-7 (2018)

4. H. Ha H, P. Schfers, Proc. 5th Int. Symp. TC28, 405 (2013)

5. J.A. Shuster, Proc. First North American Rapid Excavation and Tunneling Conf., (Baltimore: ASCE-AIME), 2, 863-895 (1972)

6. M.N. Shuplik, (Doctoral thesis, Moscow Mining Institute, 1989)

7. P.V. Nikolaev (Doctoral thesis, National University of Science and Technology MISIS, 2016)

8. K.P. Nikiforov, V.N. Kiselev, E.A. Deplan'i, Podzemnoe prostranstvo mira, 3, 24-28 (2000)

9. M.N. Shuplik, V.A. Plohih, K.P. Nikiforov, V.N. Kiselev Podzemnoe prostranstvo mira, 4, 28-38 (2001)

10. I.N. Taranenko, K.P. Nikiforov, V.N. Kiselev, Metro i tonneli, 2, 20-23 (2008)

11. V.A. Plohih, K.P. Nikiforov, V.N. Kiselev, E.A. Deplan'i, Metro i tonneli, 4, 13-18 (2001)

12. V.N. Kiselev, E.A. Deplan'i, Metro i tonneli, January, 13-18 (2003)

13. M. Pleshko, B. Meshki, M. Pleshko, MATEC Web of Conf., 170, 03023 (2018)

14. M. Pleshko, I. Voinov, A. Revyakin, MATEC Web of Conf., 106, 05004 (2017)

15. G. Romanova, M. Pleshko, M. Rossinskaya, N. Saveleva, A. Pankratenko Advances in Intelligent Systems and Computing, 692, 1111-1124 (2017) 